\title{
Análise sensorial e físico-química de geleia de achachairu (Garcinia humillis (Vahl) C. D. Adam)
}

\section{Karla Danielle de Castro Oliveira ${ }^{1}$, Sumária Sousa e Silva ${ }^{2}$, Raquel Aparecida Loss ${ }^{3}$ e Sumaya Ferreira Guedes ${ }^{4}$}

O objetivo desse trabalho foi elaborar duas formulações de geleias dos frutos de achachairu e avaliar suas caraterísticas físico-químicas (acidez, cinzas, sólidos solúveis totais, $\mathrm{pH}$ e umidade) e sensoriais (aceitação, preferência, intenção de compra, escala do ideal e índice de aceitabilidade). Uma das formulações foi elaborada com açúcar mascavo e a outra com açúcar cristal, na proporção de $50 \%$ de polpa e açúcar. A geleia com açúcar mascavo apresentou maiores médias de acidez (0,7\%), cinzas $(0,8 \%)$, sólidos solúveis totais $\left(67,4^{\circ} \mathrm{Brix}\right), \mathrm{pH}(4,1)$ e umidade $(39,1 \%)$. $\mathrm{Na}$ análise sensorial, ambas mostraram igual preferência e aceitação. No teste da escala do ideal, a geleia com açúcar cristal foi classificada como ideal pela maioria dos julgadores, de acordo com os atributos sensoriais de acidez $(76 \%)$, doçura (78\%) e viscosidade (68\%). Já a intenção de compra, ficou na escala de certamente compraria para 40 e $44 \%$ dos provadores da geleia com açúcar cristal e mascavo, respectivamente. O índice de aceitabilidade das duas formulações de geleias adoçadas com açúcar cristal e mascavo foi de $94,96 \%$ e $94,14 \%$, respectivamente. Portanto, a formulação de geleia com a polpa de achachairu tornase uma alternativa para agregar valor às frutas exóticas brasileiras.

Palavras-chave: Açúcar cristal; açúcar mascavo; frutas exóticas

\section{Sensory and physical-chemical analysis of achaicharu jam (Garcinia humillis (Vahl) C. D. Adam)}

The purpose of this study was to elaborate two formulations of achachairu fruits jam and to evaluate its physical-chemical (acidity, ash, total soluble solids, $\mathrm{pH}$ and moisture) and sensory characteristics (acceptance, preference, purchase intention, ideal scale and acceptability index). One of the formulations was made with brown sugar and the other with sanding sugar, in a proportion of $50 \%$ of pulp and sugar. The jam with brown sugar showed higher averages of acidity $(0.7 \%)$, ash $(0.8 \%)$, total soluble solids $\left(67.4^{\circ} \mathrm{Brix}\right), \mathrm{pH}(4.1)$ and moisture (39.1\%). In sensory analysis, both showed equal preference and acceptance. In the ideal scale test, sanding sugar jam was classified as ideal by most judges, according to the sensorial attributes of acidity $(76 \%)$, sweetness $(78 \%)$ and viscosity $(68 \%)$. Regarding the purchase intention, it was in the "would certainly buy" range for 40 and $44 \%$ of the sanding and brown sugar jelly tasters, respectively. The acceptability index of these two formulations of jams sweetened with sanding and brown sugar was $94.96 \%$ and $94.14 \%$, respectively. Therefore, the formulation of jam with achachairu pulp becomes an alternative to add value to Brazilian exotic fruits.

Keywords: Sanding sugar; brown sugar; exotic fruits.

${ }^{1}$ Graduada em Engenharia de Alimentos. Universidade do Estado de Mato Grosso (UNEMAT), Campus de Barra do Bugres, MT.

2 Pesquisadora, DCR/CNPq/FAPEMAT. Universidade do Estado de Mato Grosso (UNEMAT), Campus de Barra do Bugres, MT. Endereço para correspondência: Rua A, S/n, Bairro São Raimundo, CEP 78390-000, Caixa Postal 92, Barra do Bugres, Mato Grosso. + 55 (065) 3361-1413.E-mail: sumariasousa@gmail.com

${ }^{3}$ Docente do Curso de Engenharia de Alimentos. Universidade do Estado de Mato Grosso (UNEMAT), Campus de Barra do Bugres, MT.

${ }_{4}^{4}$ Docente do Curso de Engenharia de Alimentos. Universidade do Estado de Mato Grosso (UNEMAT), Campus de Barra do Bugres, MT. 


\section{INTRODUÇÃO E OBJETIVOS}

As frutas, em geral, são ricas em vitaminas, sais minerais e vários tipos de fibras que oferecem diferentes benefícios para a saúde, como o aumento da expectativa de vida, vitalidade e prevenção de doenças. Diversos estudos indicam que a ingestão de frutas, grãos e vegetais são necessários para o bom funcionamento do organismo, pois ajudam na prevenção de doenças crônicas, como o câncer, doenças neurodegenerativas, diabetes e doenças cardiovasculares. As frutas, principalmente coloridas, são fontes de vitaminas essenciais, sendo também ricas em compostos fenólicos nos quais exercem um papel fundamental no que diz respeito à prevenção de várias doenças $^{[1]}$.

No Brasil, existem muitas variedades de frutas exóticas com benefícios a saúde e de sabor agradável, que podem ser agregadas em muitos alimentos como: geleias, sorvetes, ou ainda ser consumidas in natura. Entretanto, são pouco conhecidas devido à dificuldade de manejo para algumas plantas, falta de conhecimento sobre características físicoquímica e microbiológica e clima de algumas regiões, que não são favoráveis para o cultivo ${ }^{[2]}$.

Dentre os frutos exóticos com grande potencial para comercialização que ainda é pouco conhecido no Brasil, destaca-se o Garcinia bumilis (Vahl) C. D. Adam, da família Clusiaceae, popularmente conhecido como achachairu. Seus frutos são globoso-oblongos de cor amarelo-alaranjado, apresenta casca grossa, lisa, firme e resistente e pesam aproximadamente $30 \mathrm{~g}$ (Figura 1). A polpa, de coloração branca é suculenta e de textura mucilaginosa, representando $1 / 3$ da massa média do fruto. O sabor é bem agradável e doce-acidulado equilibrado. Este fruto apresenta alto valor nutricional, entretanto por se tratar de fruto sensível e delicado quando maduro é inviável o transporte in natura devido à alta perecibilidade ${ }^{[3,4]}$.

O achachairu é amplamente distribuído na Bolívia, e está bem adaptado ao Brasil, sendo de fácil cultivo. É utilizado pela população boliviana devido às propriedades de cura digestiva e laxante sendo assim uma boa alternativa para diversificar o cardápio, visto que as frutas são essenciais e indispensáveis para o ser humano ${ }^{[5,6,7]}$. No Brasil, ele é usado na medicina popular para tratar reumatismo, inflamação, dor e distúrbios gástricos ${ }^{[4]}$.

Diante dos inúmeros benefícios provenientes da utilização deste fruto na medicina popular e poucos estudos acerca de suas propriedades nutracêuticas, o presente trabalho teve como objetivo elaborar duas formulações de geleias a partir do fruto maduro de achachairu, obtido na região de Araputanga, estado de Mato Grosso. E realizar análises físico-químicas de umidade (\%), acidez (\%), $\mathrm{pH}$, cinzas $(\%)$, sólidos solúveis totais ( $\left.{ }^{\circ} \mathrm{Brix}\right)$, relação SST/AT (ratio) bem como análise sensorial para verificar a aceitação dos produtos elaborados.

\section{MATERIAL E MÉTODOS}

\section{Obtenção da matéria-prima}

Os frutos de achachairu foram adquiridos na região de Araputanga-MT (Figura 1), geograficamente localizada no sudoeste do estado de Mato Grosso, com Latitude: $15^{\circ} 28^{\prime}$ 3" Sul e Longitude: $58^{\circ}$ 21' 22" Oeste. Destacam-se algumas características importantes do município como: o clima predominante, tropical subúmido, que compreende dois períodos bem definidos: chuva e estiagem e sua altitude média de 200 metros $^{[8]}$. 
Figura 1: Fruto maduro do achachairu. a) fruto inteiro e o b) fruto divido demonstrando a casca, polpa e sementes.
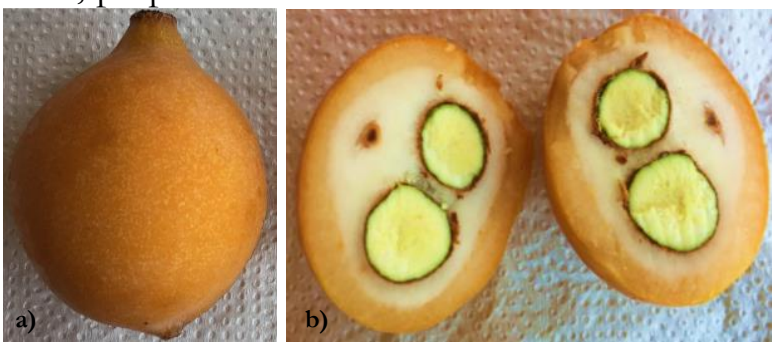

Fonte: Elaborado pelos autores. Barra do Bugres. 2018.

Os frutos foram colhidos em uma única coleta, acondicionados em caixa térmica e transportados para o laboratório de Química da Universidade do Estado de Mato Grosso, Campus de Barra do Bugres-MT, onde foram mantidos sob congelamento a $-18^{\circ} \mathrm{C}$ até $\mathrm{o}$ momento da elaboração das geleias e análises físico-químicas.

\section{Elaboração das geleias}

A geleia de achachairu foi elaborada a partir da polpa do fruto, por meio de cocção de 10 minutos, com adição de água para melhor homogeneidade com açúcar cristal e/ou mascavo. O processo de elaboração da geleia encontra-se descrito na Figura 2.

Figura 2: Etapas do processamento da geleia de achachairu.

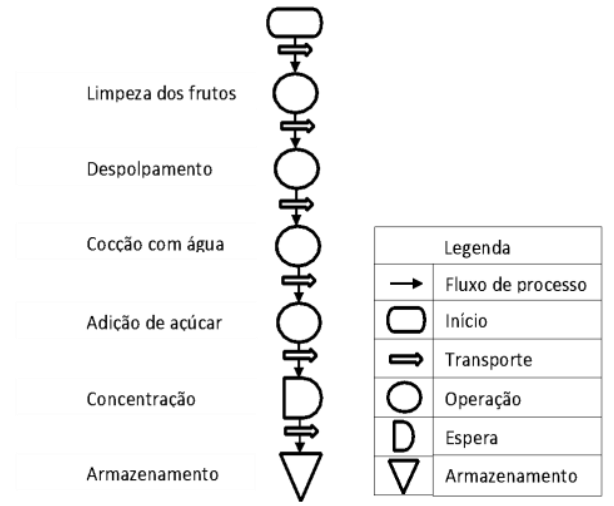

Fonte: Elaborado pelos autores. Barra do Bugres. 2018.
Foram pesadas $50 \mathrm{~g}$ de polpa, $50 \mathrm{~g}$ de açúcar (mascavo ou cristal), proporção que caracteriza geleia tipo extra, e $1 \mathrm{~g}$ de pectina, submetidas ao processo de cocção por 10 minutos e concentrada até atingir o $65^{\circ}$ Brix, valor legislado para sólidos solúveis totais em geleias de frutas. Após estas etapas, a geleia foi armazenada em potes de polietileno e conservada para a realização das análises físicoquímicas.

As formulações de geleias foram elaboradas em triplicata para maior confiabilidade dos resultados.

Posteriormente, foram realizadas análises físico-químicas das geleias quanto ao teor de sólidos solúveis totais (SST) expressos em ${ }^{\circ}$ Brix, $\mathrm{pH}$, acidez titulável (AT), expressa em $\mathrm{g}$ ácido cítrico, relação SS/AT (ratio), umidade e cinzas de acordo com a metodologia preconizada pelo Instituto Adolfo Lutz, $(2008)^{[9]}$. Todas as análises foram realizadas em triplicata.

\section{Análise sensorial}

A análise sensorial foi conduzida somente após a aprovação pelo Comitê de Ética em Pesquisa (CEP), da Universidade do Estado de Mato Grosso (Número do parecer: 1.782.791). Os testes foram realizados com a participação de 50 julgadores não treinados. Logo após a concordância e assinatura do Termo de Consentimento Livre e Esclarecido (TCLE), os participantes foram direcionados para cabines individuais, com iluminação branca. As amostras (geleia com açúcar cristal e açúcar mascavo) foram oferecidas aos provadores em copos plásticos descartáveis de $50 \mathrm{~mL}$, codificados com números aleatórios de três dígitos, à temperatura ambiente, acompanhadas de biscoitos laminados salgados e água. Os testes estatísticos seguiram a metodologia descrita por Minim (2013) ${ }^{[10]}$. Também foi avaliado o índice de aceitabilidade (IA) dos produtos elaborados, por meio da expressão IA 
$(\%)=\mathrm{A} \times 100 / \mathrm{B}$, sendo que $\mathrm{A}$ representa a nota média obtida para o produto e $\mathrm{B}$ a nota máxima dada ao produto $^{[11]}$.

\section{Teste de preferência}

O primeiro item avaliado foi a preferência do julgador através do teste de comparação pareada, onde o julgador foi convidado a circular a amostra que teve maior preferência. A ordem de apresentação das amostras foram casualizada entre os julgadores, para evitar respostas tendenciosas e atender as pressuposições dos testes estatísticos.

\section{Teste de aceitação e intenção de compra}

Foram avaliados também os atributos sensoriais tais como: atributo global, aroma, sabor, textura e cor, por meio de uma escala hedônica estruturada de nove pontos, com os termos "desgostei extremamente" (1) e "gostei extremamente" (9) nos extremos da escala.

Para avaliar a atitude do consumidor em uma situação hipotética de compra do produto, foi utilizada uma escala de intenção de compra de cinco categorias, com os termos "certamente não compraria" (1) e "certamente compraria" (5) nos extremos da escala.

\section{Teste escala do ideal}

Foi realizado ainda a análise da escala do ideal (Just Right Scales) a partir das informações dos atributos sensoriais da acidez, doçura e viscosidade nas amostras de geleia que estariam no estado "ideal, baixa ou elevada". Para análise dos dados neste teste estatístico, foi utilizado o percentual dos julgadores que responderam nas escalas apresentadas.

\section{Análise estatística}

Para a realização das análises estatísticas dos resultados utilizou-se o teste de Tukey, em nível de significância de $5 \%$, através do software Statistica versão $7.0^{[12]}$.

\section{RESULTADOS E DISCUSSÃO}

As geleias apresentaram colorações diferentes, assim como a textura, devido os diferentes tipos de açúcares utilizados na elaboração de cada formulação (Figura 3). A geleia feita com açúcar cristal (Figura 3a) obteve cor e aroma característicos do fruto, tal como sugerido pela Comissão Nacional de Normas e Padrões para Alimentos (Resolução CNNPA n. $12,2005)^{[13]}$. Já a geleia com açúcar mascavo (Figura 3b) apresentou cor escura e cheiro específico do açúcar mascavo, lembrando um odor de cana-de-açúcar.

Figura 3: Geleias de achachairu adoçadas com diferentes tipos de açúcares. (a) açúcar cristal e (b) açúcar mascavo.
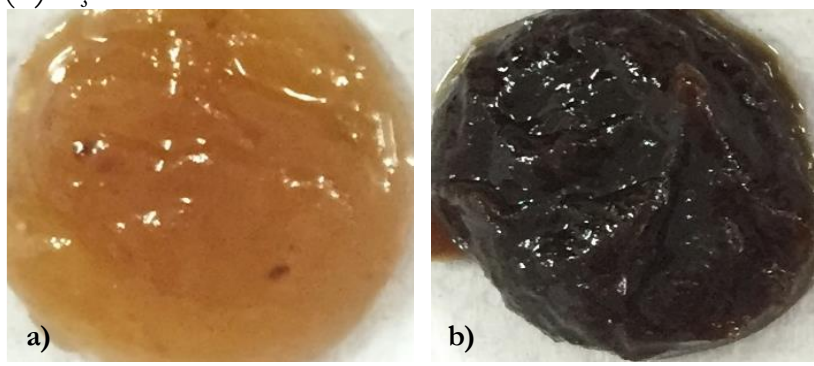

Fonte: Elaborado pelos autores. Barra do Bugres. 2018.

O açúcar é componente essencial na elaboração de geleias e pode interferir nas características sensoriais (sabor, textura e cor), além de contribuir para o sabor característico desses produtos e na sua consistência ${ }^{[14]}$. O açúcar mais utilizado no preparo desses produtos é a sacarose, na forma de açúcar cristal. No entanto, no beneficiamento desse açúcar, em especial nas etapas de extração e refino são acrescentados agentes clarificantes, a fim de obter um produto de cor mais clara. Já o açúcar mascavo não passa pela etapa de refino, resultando em um produto final de coloração mais escura. Além disso, o açúcar mascavo apresenta maior quantidade de nutrientes e maior umidade. Desta forma, o açúcar mascavo difere do açúcar cristal, principalmente, pela sua 
coloração escura, e pelo menor percentual de sacarose, podendo ser utilizado como uma alternativa para a elaboração de geleias ${ }^{[15]}$.

A quantidade de açúcar pode ser expressa em função do teor de sólidos solúveis totais ( ${ }^{\circ}$ Brix). O teor de sólidos solúveis em geleias é legislado pela ANVISA, (Resolução CNNPA n. 12 , de 2005) ${ }^{[13]}$, que determina valores mínimos de $65^{\circ}$ Brix.
A Tabela 1 apresenta os resultados das análises físico-químicas das geleias de achachairu. Conforme observado, foram obtidos valores de $65,71{ }^{\circ}$ Brix para as geleias adoçadas com açúcar cristal e $67,4{ }^{\circ}$ Brix para açúcar mascavo, ambas de acordo com os parâmetros legislado.

Tabela 1: Análise físico-química das geleias de achachairu, elaboradas com açúcar cristal e mascavo.

\begin{tabular}{cccc}
\hline Parâmetros físico- & \multicolumn{2}{c}{ Formulações } \\
\cline { 2 - 4 } químicos & Cristal & Mascavo & CV (\%) \\
\hline Umidade $(\%)$ & $37,11 \pm 2,72^{\mathrm{a}}$ & $39,12 \pm 1,12^{\mathrm{a}}$ & 6,04 \\
Cinzas (\%) & $0,28 \pm 0,03^{\mathrm{a}}$ & $0,80 \pm 0,02^{\mathrm{b}}$ & 52,73 \\
SST ( ${ }^{\circ}$ Brix) & $65,71 \pm 0,45^{\mathrm{a}}$ & $67,40 \pm 0,17^{\mathrm{a}}$ & 4,14 \\
pH & $3,68 \pm 0,01^{\mathrm{a}}$ & $4,09 \pm 0,002^{\mathrm{b}}$ & 6,41 \\
AT (\% de ácido cítrico) & $0,50 \pm 0,004^{\mathrm{a}}$ & $0,69 \pm 0,01^{\mathrm{b}}$ & 17,63 \\
SST/AT & $130,8 \pm 7,89^{\mathrm{a}}$ & $97,32 \pm 2,92^{\mathrm{b}}$ & 16,76 \\
\hline
\end{tabular}

*Valores com letras distintas diferem na mesma linha pelo teste de Tukey a $5 \%$ de probabilidade. *

Fonte: Elaborado pelos autores. Barra do Bugres. 2018.

De acordo com Soler $(1991)^{[14]}$ é importante controlar a concentração sólidos solúveis próximos a $67,5^{\circ}$ Brix, pois, se os valores forem acima disso podem favorecer a formação de cristalização da sacarose, e se forem abaixo, a geleia pode apresentar baixa viscosidade, com textura insatisfatória.

De acordo com a Tabela 1 pode-se observar que a acidez encontrada nas duas geleias apresentou resultados dentro do padrão recomendado por Mendonça, Rodrigues e Zambiazi (2000) ${ }^{[15]}$, uma vez que a acidez deve ser no mínimo de $0,3 \%$ e no máximo de $0,8 \%$.

$\mathrm{Na}$ produção de geleias, a acidez apresenta uma relação importante com o pH para o controle da qualidade. Pode-se observar que a geleia preparada com açúcar mascavo apresenta $\mathrm{pH}$ e acidez maior do que a preparada com açúcar cristal. Os maiores valores de $\mathrm{pH}$ e acidez para a geleia preparada com açúcar mascavo pode ser atribuído à presença de impurezas com caráter ácido fraco presentes no açúcar mascavo. Outro indicativo que o açúcar mascavo é o responsável pela elevação do $\mathrm{pH}$ é o fato da fruta in natura apresentar $\mathrm{pH}$ de 3,2 e a geleia de achachairu elaborada com açúcar cristal pH de 3,68. Já para a geleia elaborada com açúcar mascavo foi observado a elevação do $\mathrm{pH}$ para 4,09.

Apesar do $\mathrm{pH}$ não ser um parâmetro legislado, recomenda-se, para geleias, valores na faixa de 3 a $4^{[16]}$. Desta forma, ambas as geleias se encontram dentro da faixa recomendada pelo autor. Além disso, o pH é um dos atributos de maior importância na caracterização físicoquímica de alimentos em geral, uma vez que valores abaixo de 4,0 podem inibir o crescimento de alguns micro-organismos patogênicos, além de não necessitar de adição de agentes químicos como acidulantes ${ }^{[17]}$. 
De acordo com Gava, Silva e Frias (2008) ${ }^{[18]}$, a formação do gel ocorre entre determinados valores de $\mathrm{pH}$, em condições ideais para a formação do gel na faixa de $\mathrm{pH} 3,2$ a 3,5 considerando o teor de sólidos solúveis totais próximos de $65 \%$. Valores de $\mathrm{pH}$ menores, aumentam a tendência de sinérese, ou seja, do desprendimento de água do gel, dificultando a geleificação e comprometendo a textura da geleia. Ambas as geleias apresentaram uma textura firme, de modo que o $\mathrm{pH}$ de 4,09 obtido pela geleia elaborada com açúcar mascavo não comprometeu a formação do gel.

A relação SST/AT foi maior para a geleia elaborada com açúcar cristal, o que o pode estar relacionada com a menor acidez desta geleia. A relação entre o teor de sólidos solúveis totais e a acidez titulável está relacionada com o balanço entre açúcares e ácidos orgânicos presentes na fruta, sendo importante indicativo do sabor ${ }^{[19]}$. Os valores obtidos no presente estudo são superiores aos obtidos por Mota $(2006)^{[20]}$ em geleias de amora preta $(30,50$ a $38,65)$ e inferior ao obtidos por Oliveira et al. $(2016)^{[19]}$ em geleia de laranja $(155,65)$ e laranja com hortelã $(159,82)$.

Quanto aos valores de resíduo mineral fixo (cinzas) obtidos para a geleia, a formulação elaborada com açúcar cristal (0,28 \%) apresentou menor quantidade de cinzas, em comparação com a geleia de açúcar mascavo $(0,80 \%)$. A diferença no teor de minerais pode estar associada a composição do adoçante utilizado, pois o açúcar mascavo é rico em minerais, mantendo as características mais próximas da cana-de-açúcar, fator que contribuiu para a elevação do teor de cinzas nas geleias em comparação com o açúcar cristal.

Os valores de umidades obtidas nas geleias foram de 37,11 \% para a geleia elaborada com açúcar cristal, e 39,12 \% para o açúcar mascavo. A maior umidade para a formulação com açúcar mascavo pode ser devido ao fato que em relação ao cristal ou refinado, a umidade do mascavo é quatro vezes maior. As umidades são semelhantes às obtidas por Fernandes et al. $(2013)^{[16]}$, na elaboração de geleia de goiaba com açúcar cristal $(36,87 \%)$ e mascavo $(38,76 \%)$ e Freitas et al. (2008) ${ }^{[21]}$ na elaboração de geleia de gabiroba adicionada de $1 \%$ de ácido cítrico $(39,35 \%)$ e $1,5 \%$ ácido cítrico (40,46\%). Valores superiores de umidade foram encontrados por Mota $(2006)^{[20]}(42,84$ a $49,82 \%)$ para geleias elaboradas a partir de diferentes cultivares de amora preta. Já Oliveira et al. (2016) ${ }^{[22]}$ encontraram valores de umidade inferiores para geleias de laranja enriquecida com aveia, obtendo 34,63\% de umidade para geleia com $1,5 \%$ de aveia e $38,14 \%$ para a formulação com $3 \%$ de aveia. A legislação brasileira estabelecida pela Agencia Agência Nacional de Vigilância Sanitária (Brasil, 2005) ${ }^{[13]}$, não estabelece valor limite para a umidade de geleias de frutas.

Dessa forma, as geleias obtidas apresentam caracterização físico-química adequada com os parâmetros legislados de sólidos solúveis totais, e valores aceitáveis de acidez, pH e umidade.

$\mathrm{Na}$ avaliação sensorial, pelo teste de comparação pareada, não foi possível afirmar qual das geleias apresentou maior preferência, uma vez que para 50 julgadores, no mínimo 33 deveriam apontar uma das geleias como preferida. No entanto, apenas 27 julgadores marcaram a geleia elaborada com açúcar cristal como preferida e 22 optaram pela geleia com açúcar mascavo. Isso é comum entre testes de avaliação sensorial, pois estes normalmente diferem entre si com relação ao grau de gostar ou desgostar das amostras avaliadas ${ }^{[23]}$.

Os resultados obtidos na avaliação sensorial de atributo global, aroma, cor, sabor e textura são apresentados na Tabela 2 pelas médias atribuídas pelos provadores para cada atributo analisado. 
Tabela 2: Análise sensorial das geleias de achachairu, elaboradas com açúcar cristal e mascavo.

\begin{tabular}{ccc}
\hline \multirow{2}{*}{$\begin{array}{c}\text { Atributos } \\
\text { sensoriais }\end{array}$} & \multicolumn{2}{c}{ Formulações } \\
\cline { 2 - 3 } & Cristal & Mascavo \\
\hline Aroma & $7,16 \pm 1,35^{\mathrm{a}}$ & $6,82 \pm 1,68^{\mathrm{a}}$ \\
Atributo Global & $7,90 \pm 1,03^{\mathrm{a}}$ & $7,52 \pm 1,32^{\mathrm{a}}$ \\
Cor & $7,20 \pm 1,35^{\mathrm{a}}$ & $7,72 \pm 1,67^{\mathrm{a}}$ \\
Sabor & $7,81 \pm 1,30^{\mathrm{a}}$ & $7,18 \pm 1,67^{\mathrm{a}}$ \\
Textura & $7,44 \pm 1,37^{\mathrm{a}}$ & $7,10 \pm 1,60^{\mathrm{a}}$ \\
\hline
\end{tabular}

*Valores com letras distintas diferem na mesma linha pelo teste de Tukey a $5 \%$ de probabilidade.

Fonte: Elaborado pelos autores. Barra do Bugres. 2018.

Pela Tabela 2, pode-se observar que as amostras obtiveram boa aceitação, todos os atributos avaliados apresentaram médias superiores a 7 (gostei moderadamente), apenas o atributo aroma da geleia com açúcar mascavo teve uma leve diferença de 6,82 de média, constando o score como gostei moderadamente, porém não diferiu de acordo com o teste Tukey a 5\% de probabilidade.

Entre as geleias elaboradas com açúcar cristal e açúcar mascavo, os atributos aroma, atributo global, cor, sabor e textura não diferiram entre si, resultando assim a aceitabilidade de ambas as geleias $(\mathrm{p}<0,05)$. Devido a coloração atraente do produto elaborado, comprova-se que a produção da geleia não prejudicou a pigmentação da polpa da matéria-prima quando produzida com açúcar cristal, esse atributo faz-se um dos mais importantes na comercialização de alimentos por ser o primeiro critério de aceitação ou rejeição a ser analisado pelos consumidores. No entanto, a cor escura característica do açúcar mascavo não interferiu na aceitação da geleia, uma vez que as médias obtidas foram semelhantes às da geleia elaborada com açúcar cristal.

No teste da escala do ideal, nas informações dos atributos sensoriais da acidez, doçura e viscosidade (Gráfico 1), observou-se que a geleia de açúcar cristal distinguiu-se da geleia de açúcar mascavo somente em relação a acidez, uma vez que $76 \%$ dos provadores classificaram a acidez da geleia elaborada com açúcar cristal como ideal, enquanto que para o açúcar mascavo o percentual foi de $52 \%$. Além disso, $10 \%$ dos provadores consideraram que a acidez da geleia elaborada com açúcar mascavo estava elevada, enquanto que para o açúcar cristal esse percentual foi de 6\%. Esses resultados estão de acordo com os observados na caracterização físico-química, uma vez que a acidez da geleia com açúcar mascavo foi superior.

Uma alta acidez pode influenciar na aceitação do produto e/ou necessidade de aumento do teor de açúcares da amostra, tornando o produto com sabor muito doce. Dessa forma é importante verificar estes valores para que não estejam muito altos $\mathrm{e}$ consequentemente, evitar a rejeição da geleia pelo consumidor. No teste da escala do ideal, $78 \%$ dos provadores classificaram como ideal e $10 \%$ como elevada a doçura da geleia elaborada com açúcar cristal. Para o açúcar mascavo $72 \%$ dos provadores consideraram a doçura ideal e $14 \%$ elevada. Esses resultados comprovam que apesar da geleia elaborada com açúcar mascavo ter apresentado uma acidez maior, não comprometeu a aceitação do produto.

Segundo Ribeiro et al. (2016) ${ }^{[24]}$ a acidez está relacionada com a presença de substâncias ácidas naturalmente contidas em frutas. Esses compostos, em especial o ácido cítrico, auxiliam no desenvolvimento da textura adequadas das geleias, tornando esse parâmetro físico-químico um importante parâmetro no controle de qualidade de geleias. Além disso, de acordo com Gava, Silva \& Frias $(2008)^{[18]}$, em pH abaixo de 3,2 pode dificultar a formação de gel, resultando em geleias com baixa viscosidade e 
com aspecto de 'mole'. Apesar da geleia elaborada com açúcar mascavo ter apresentado uma acidez um pouco mais elevada e $\mathrm{pH}$ acima do considerado ideal para a formação do gel, esses valores não comprometeram a textura das geleias uma vez que, no teste sensorial da escala do ideal, 68\% dos provadores classificaram como ideal a viscosidade da geleia com açúcar cristal, enquanto que para o açúcar mascavo o percentual foi de $66 \%$. Além disso, para ambas as geleias, e mesmo percentual de provadores $(8 \%)$ consideraram a viscosidade baixa.

Gráfico 1: Avaliação dos atributos sensoriais de acidez, doçura e viscosidade das geleias de achachairu. a) açúcar cristal; b) açúcar mascavo.
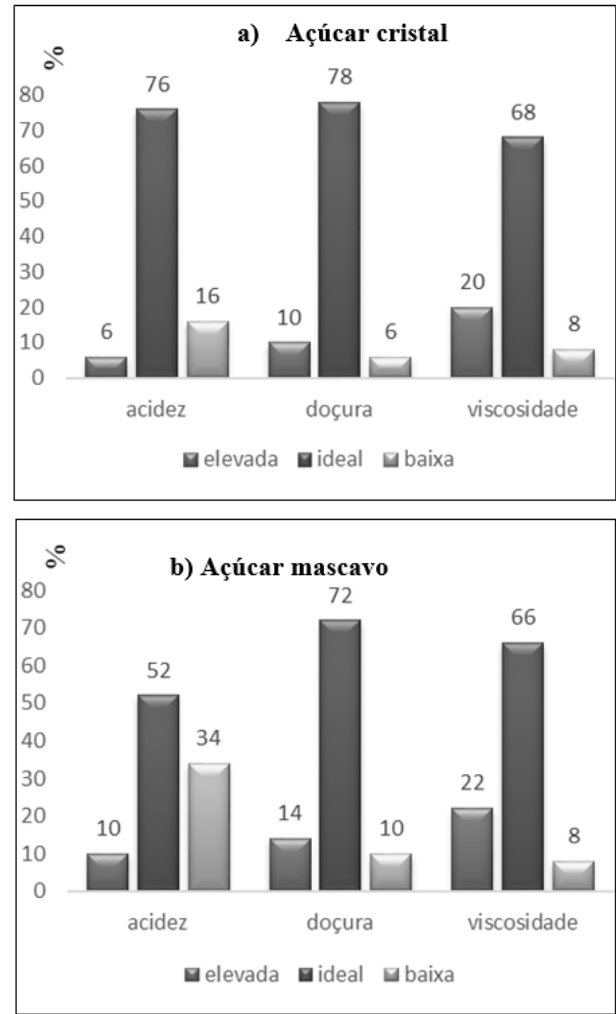

Fonte: Elaborado pelos autores. Barra do Bugres. 2018.

A Tabela 3 apresenta a intenção dos julgadores em relação às amostras das geleias, revelando uma maior frequência de resultados entre os conceitos de "certamente compraria" e "provavelmente compraria". Essas respostas constituem que escala de atitude foram positivas em relação às duas geleias, com $40 \% \mathrm{e}$ $44 \%$ de açúcar cristal e mascavo certamente comprariam.

Tabela 3: Avaliação da intenção de compra pelos provadores das geleias de achachairu, elaboradas com açúcar cristal e açúcar mascavo.

Formulações

\begin{tabular}{ccc}
\hline Atitude de compra & Cristal & Mascavo \\
\hline $\begin{array}{c}\text { Certamente } \\
\text { compraria }\end{array}$ & $40 \%$ & $44 \%$ \\
$\begin{array}{c}\text { Provavelmente } \\
\text { compraria }\end{array}$ & $40 \%$ & $28 \%$ \\
$\begin{array}{c}\text { Talvez compraria/ } \\
\text { Talvez não compraria } \\
\text { Provavelmente não } \\
\quad \text { compraria }\end{array}$ & $16 \%$ & $12 \%$ \\
$\begin{array}{c}\text { Certamente não } \\
\text { compraria }\end{array}$ & $0 \%$ & $14 \%$ \\
\hline
\end{tabular}

Fonte: Elaborado pelos autores. Barra do Bugres. 2018.

As particularidades no processo tecnológico na produção dos açúcares utilizados na elaboração das geleias podem modificar as características físicas, químicas e sensoriais, o que pode interferir na aceitação dos produtos $^{[15]}$.

$O$ índice de aceitabilidade obtido pelos atributos sensoriais das formulações de geleias adoçadas com açúcar cristal e mascavo, foram, respectivamente, $94,96 \%$ e 94,14\%. Segundo Dutcosky $(2011)^{[25]}$, para que o produto seja considerado com boa aceitação é necessário que o índice de aceitabilidade seja igual ou superior a $70 \%$. Assim, é possível afirmar que ambas formulações apresentam potencial de consumo.

Desta forma, analisando os testes sensoriais como um todo, não foi possível determinar dentre as geleias qual foi a que apresentou uma 
maior aceitação. No entanto, a geleia adoçada com açúcar cristal foi apontada como ideal em relação a acidez por um maior número de julgadores. Além disso, a geleia adoçada com açúcar cristal foi a mais citada no teste de intenção de compra nas escalas de provavelmente compraria e talvez compraria/talvez não compraria.

\section{CONCLUSÃO}

Dessa forma, as duas formulações de geleias elaboradas apresentaram caracterização físicoquímica adequada com os parâmetros legislados de sólidos solúveis totais, e valores aceitáveis de acidez e pH. Em relação a análise sensorial, tanto a geleia elaborada com açúcar mascavo quanto a elaborada com açúcar cristal, apresentaram atributos de qualidade e aceitação pelos provadores, sendo que no aspecto geral, ambas as geleias apresentaram igual aceitação. Portanto, a formulação de geleia com a polpa de achachairu torna-se uma alternativa para consumo e com potencial de aplicação tecnológica de frutas exóticas através da elaboração de novos produtos.

\section{AGRADECIMENTOS}

Os autores agradecem à Fundação de Amparo à Pesquisa do Estado de Mato Grosso (processo $\mathrm{n}^{\circ} 0575980 / 2018$ ), e ao Conselho Nacional de Desenvolvimento Científico e Tecnológico pela bolsa de pesquisa DCR (processo n³13859/2017-5).

\section{REFERÊNCIAS}

[1] Silva Júnior, JF, Bezerra, JEF \& Lederman, IE. Recursos genéticos e melhoramento de fruteiras nativas e exóticas em Pernambuco. In: Queiróz MA de, Goedert CO \& Ramos SRR. (org.), Recursos genéticos e melhoramento de plantas para o Nordeste Brasileiro (on line). Embrapa Semi-Árido, Petrolina, Brasil/Embrapa Recursos Genéticos e Biotecnologia, Brasília; 1999.
[2] Vanin, CR. Araçá amarelo: atividade antioxidante, composição nutricional e aplicação em barra de cereais [dissertação]. Londrina: Universidade Tecnológica Federal do Paraná; 2015. 117 p.

[3] Soares, ES. Caracterização de aditivos para secagem de araçá-boi (Eugenia stipitata McVaugh) em leito de espuma [dissertação]. Itapetinga: Universidade Estadual do Sudoeste da Bahia; 2009. 89 p.

[4] Barbosa, W, Chagas, EA, Martins, L, Pio R, Tucci, MLS, Artioli, FA. Germinação de sementes e desenvolvimento inicial de plântulas de Achachairu. Revista Brasileira de Fruticultura. 2008; 30(1):263-266.

[5] Janick, J. \& Paull, RE. Rheedia laterifolia Achachairú. In: The encyclopedia of Fruit \& Nuts. Cambridge, UK: CABI; 2008.

[6] Lorenzi, H, Sartori, SF, Bacher, LB \& Lacerda, MTC. Frutas brasileiras e exóticas cultivadas (de consumo in natura). São Paulo: Instituto Plantarum de Estudos da Flora; 2006.

[7] Barbosa, E. \& Artioli, F. A. A. Fruta achachairú. 2007. Disponível em: http://www.infobibos.com/Artigos/2007_1/a chachairu/index.htm.

[8] Instituto Brasileiro de Geografia e Estatística (IBGE). Divisão Territorial do Brasil. Divisão Territorial do Brasil e Limites Territoriais; 2008.

[9] Zenebon O, Pascuet NS \& Tiglea P (org.) Métodos físico-químicos para análise de alimentos São Paulo: Instituto Adolfo Lutz; 2008.

[10] Minim, VPR. Análise Sensorial: Estudos com consumidores. Viçosa: Editora da UFV; 2013. 
[11] Souza HS, Santos AM, Silva AMO, Ferreira IM, Nunes TP, Carvalho MG. Elaboração e avaliação da qualidade de geleia de umbu (Spondias Tuberosa Arr. C.) e mangaba (HancorniaSpeciosa G.) com alegação funcional. Segurança Alimentar e Nutricional, 2018, 25(3):104-113.

[12] Calado, V \& Montgomery, D (org.) Planejamento de experimentos usando Statistica. Rio de Janeiro: E-papers serviços editoriais; 2003.

[13] BRASIL. Ministério da Saúde. Agência Nacional de Vigilância Sanitária. Resolução RDC n ${ }^{\circ} 272$ de 22 de Setembro de 2005. Aprova Regulamento Técnico para produtos vegetais, produtos de frutos e cogumelos comestíveis. Diário Oficial [da] República Federativa do Brasil, Brasília, DF. 23 de Setembro de 2005.

[14] Soler, MP. Industrialização de Geleias: Processamento Industrial. Campinas: Instituto de Tecnologia de Alimentos: ITAL; 1991.

[15] Mendonça, CR, Rodrigues, RS \& Zambiazi, RC. Açúcar mascavo em geleiadas de maçã. Ciência Rural. 2000; 30(6): 1053-1058.

[16] Fernandes, LGV, Braga, CMP, Kajishima, S, Spoto, MHF, Borges, MTMR \& VerrumaBernardi, MR. Caracterização físico-química e sensorial de geleias de goiaba preparadas com açúcar mascavo. Revista Brasileira de Produtos Agroindustriais. 2013; 15(2): 167-172.

[17] Gomes RB, Santos MB, Cardoso RL, Tavares JTQ, Cunha DS. Elaboração e avaliação físico-químico e sensorial de geleia de maracujá com cenoura, 2013, 9(16): 2765-2770.
[19] Oliveira MMT, Braga TR, Pinheiro GK, Silva LR, Vieira CB, Torres LBV. Parâmetros físico-químicos, avaliação microbiológica e sensorial de geleias de laranja orgânica com adição de hortelã. Revista de la Facultad de Agronomía, La Plata, 2016), 115 (1): 29-34.

[20] Mota RV. Caracterização física e química de geleia de amora-preta. Ciência e Tecnologia de Alimentos, 2006, 26 (3):539-543.

[21] Freitas FB, Cândido TLN, Silva MR. Geleia de gabiroba: avaliação da aceitabilidade e características físicas e químicas. Pesquisa Agropecuária Tropical, 2008, 38 (2): 87-94.

[22] Oliveira CFD, Pinto EG, Tomé AC, Quintana RC, Dias BF. Desenvolvimento e caracterização de geleia de laranja enriquecida com aveia. Revista de Agricultura Neotropical, 2016, 3(3)3: 20-23.

[23] Valim, MF, Marcellini, PS, Cavalheiro, S, Demarchi, R \& Serafim, E. Preference Mapping to asses consumers orange juice preference. Fruit Processing. 2001; 3(3): 90-94.

[24] Ribeiro, LMP, Damasceno, KA, Gonçalves, RMS, Gonçalves, CAA, Alves, AN \& Cunha, MF. Acidez, sua relação com pH e qualidade de geleias e doces em barra. Boletim Técnico IFTM. 2016; 2(2): 14-19.

[25] Dutcosky SD. Análise sensorial de alimentos. 3. ed. Curitiba: Champagnat, 2011.

[18] Gava, AJ, Silva, CAB \& Frias, JRG. Tecnologia dos Alimentos: princípios e aplicações. São Paulo: Nobel; 2008. 